\title{
Atividades de aventura na educação física escolar: uma análise nos periódicos nacionais
}

\author{
Adventure activities in school physical education: an \\ analysis in national periodics
}

\section{Actividades de aventura en la educación física escolar: un análisis en revistas nacionales}

\author{
iD@ Jayson Gonçalves \\ Universidade do Estado de Santa Catarina, Florianópolis, Santa Catarina, Brasil \\ jayson.edf@gmail.com \\ iD 9 \\ Jéssica Cozza \\ Universidade do Estado de Santa Catarina, Florianópolis, Santa Catarina, Brasil \\ jessicacozza@hotmail.com \\ iD Fernanda Granato de Souza \\ Universidade do Estado de Santa Catarina, Florianópolis, Santa Catarina, Brasil \\ nandagranato@yahoo.com.br \\ iD Marcos Paulo Vaz de Campos Pereira \\ Universidade do Estado de Santa Catarina, Florianópolis, Santa Catarina, Brasil \\ marcosp.pereira46@gmail.com \\ iD Gelcemar Oliveira Farias \\ Universidade do Estado de Santa Catarina, Florianópolis, Santa Catarina, Brasil \\ fariasgel@hotmail.com
}

\begin{abstract}
Resumo: As práticas corporais de aventura na escola ainda são um recente conteúdo e carecem de investigações centradas na área da Educação Física. Nesse sentido, o objetivo deste estudo é analisar a produção científica em periódicos nacionais sobre as atividades e os esportes de aventura no contexto escolar. Caracterizada como bibliográfica, esta
\end{abstract}


pesquisa utilizou como fonte de informação os periódicos na área da Educação Física classificados como A2, B1 e B2, mediante os descritores atividades de aventura e esportes de aventura. A partir desses critérios, foram analisados 5 artigos, nas categorias objetivo, método e principais resultados. Esperava-se encontrar um contingente maior de estudos nos periódicos investigados. Todavia, considera-se que o objetivo inicial foi atingido, pois revelou que há a necessidade de ampliar as investigações sobre o tema práticas corporais de aventura.

Palavras-chave: Atividades de aventura. Esportes de aventura. Educação Física e treinamento. Escola.

Abstract: The body adventure practices in the school are still a recent content and need research focused on Physical Education, in this sense, the aim of the study is to analyze the scientific production in national journals about adventure activities and sports in the school context. Characterized as a bibliography, the periodicals in Physical Education classified as A2, B1 and B2 were used as sources of information, using the descriptors adventure activities and adventure sports. Considering the analysis of the established criteria, 5 articles were analyzed in the objective, method and main results categories. It was expected to find a larger contingent of studies in the investigated periodicals, however, it is considered that the initial objective was reached, because it revealed that there is a need to broaden the investigations on the topic of corporal adventure practices.

Keywords: Adventure activities. Adventure Sports. Physical Education and training. School.

Resumen: Las prácticas corporales de aventura en la escuela siguen siendo un contenido reciente y la falta de investigaciones centradas en el área de Educación Física. En este sentido, el objetivo del estudio es analizar la producción científica en revistas nacionales sobre las actividades y los deportes de aventura en el contexto escolar. Caracterizados como bibliográficos, las revistas en el área de Educación Física clasificadas como A2, B1 y B2 se utilizaron como fuente de información, utilizando los descriptores de actividades de aventura y deportes de aventura. Considerando el análisis de los criterios establecidos, se analizaron 5 
artículos, en las categorías objetivo, método y principales resultados. Se esperaba encontrar un mayor contingente de estudios en las revistas investigadas. Sin embargo, se considera que se logró el objetivo inicial, ya que reveló que es necesario ampliar las investigaciones sobre el tema de las prácticas de aventura corporal.

Palabras clave: Actividades de aventura. Deportes de aventura. Educación física y entrenamiento. Escuela.

Submetido em: 25/06/2018

Aceito em: 12/11/2018 


\section{Introdução}

As atividades de aventura têm evoluído como um fenômeno cultural em diversas comunidades, com grande destaque no contexto do lazer e do turismo, tornando-se uma realidade na sociedade. Associadas aos interesses da sociedade atual, a educação ambiental e as atividades de aventura têm ganhado destaque na comunidade científica, o que de certo modo acompanha o crescimento da prática da atividade física (FRANCO, 2013; FIGUEIREDO; SCHWARTZ, 2013).

Por essa razão, a demanda de profissionais capacitados para o desenvolvimento da prática das atividades de aventura tem crescido, visto que os parques florestais, os espaços planejados, os espaços indoors e abertos exigem profissionais com determinado conhecimento e competência para a intervenção (BORBA; AZEVEDO, 2007; AURICCHIO, 2017). O professor de Educação Física está diretamente ligado a essa demanda e cabe a ele fomentar as atividades de aventura na escola e demais espaços, no entendimento de que estes se configuram como excelentes contextos para a ampliação dessa prática esportiva (FRANCO; CAVASINI; DARIDO, 2014; BUNGENSTAB et al., 2017).

Na perspectiva de Guimarães et al. (2001), as aulas de Educação Física são voltadas à dimensão procedimental, dando ênfase prioritariamente às técnicas esportivas. Entretanto, o professor de Educação Física deve proporcionar ao aluno múltiplas práticas, além das modalidades esportivas tradicionais, em sua intervenção no meio escolar, superando o predomínio de aulas tradicionais esportivizadas no contexto escolar (SCAGLIA, 2007).

No que se refere à legislação brasileira, a Lei de Diretrizes e Bases da Educação Básica aborda a questão da Educação Ambiental (BRASIL, 1996), já a Lei nº 9.795/1999 institui a Política Nacional de Educação Ambiental (BRASIL, 1999) e o Parecer CNE/ CP n 14/2012 trata das Diretrizes Curriculares Nacionais (BRASIL, 
2013). Com a elaboração dos Parâmetros Curriculares Nacionais (BRASIL, 1998), as atividades de aventura surgem como conteúdo da Educação Física com as denominações de Esportes Radicais e Atividades de Lazer Ecológico. Por conseguinte, o professor de Educação Física tem a oportunidade de aprofundar o tema e elaborar os conceitos e os procedimentos de intervenção na escola. Atualmente, no documento em vigência da Base Nacional Comum Curricular (BNCC), as atividades de aventura receberam uma nova nomenclatura, passando a serem chamadas de práticas corporais de aventura (BRASIL, 2017).

As atividades de aventura podem ser caracterizadas por sua imprevisibilidade atrelada à vertigem e ao risco, mas são diferenciadas de acordo com o local em que são praticadas, já que podem ser realizadas em ambientes naturais ou adaptados, enquanto as práticas de aventura urbanas em exploram os ambientes das cidades. As modalidades dessas práticas corporais de aventura são diversas: corrida orientada, corrida de aventura, rapel, tirolesa, parkour, skate, patins, dentre outras (BRASIL, 2017).

As práticas corporais de aventura têm sido desenvolvidas no contexto escolar com o objetivo de capacitar a prática docente. Nesse sentido, Borba e Azevedo (2007) destacam a escalada como uma estratégia pedagógica para promoção da educação inclusiva. Autores salientam os desafios à inteligência humana que a prática da escalada na escola pode oferecer. As situações-problemas criadas nesse processo proporcionam risco ao praticante, melhorando assim tanto a consciência corporal quanto a autonomia, além de inúmeras habilidades motoras, resgatando a relação do ser humano com a natureza (BORBA; AZEVEDO, 2007; BUNGENSTAB et al., 2017).

Estudos centrados nas práticas corporais de aventura na escola buscam identificar as estratégias do conteúdo, pois a sua inserção ainda é recente e carece de investigações ampliadas na área da Educação Física (HYNDMAN, 2016; INÁCIO et al., 2016; PAIXÃO, 2017). Assim, faz-se necessário compreender como as atividades 
de aventura no ambiente escolar estão sendo sistematizadas em periódicos na área da Educação Física.

Uma das maneiras de averiguar como este tema tem sido tratado é analisando a produção científica em periódicos nacionais com Qualis elevado. Dessa maneira, é possível captar indícios sobre as concepções e os pressupostos que ancoram a temática, pois o conhecimento sobre o que tem sido produzido permite identificar os avanços e o processo de inclusão de tais conteúdos nos projetos pedagógicos e nos planos de ensino da Educação Física. Desta forma, este estudo tem como objetivo analisar a produção científica em periódicos nacionais sobre as atividades de aventura e os esportes de aventura no contexto escolar.

\section{Método}

O estudo se caracteriza como bibliográfico e visa a analisar a produção científica em periódicos nacionais sobre as atividades de aventura e os esportes de aventura no contexto escolar. Para a coleta de dados foram selecionadas as revistas da área da Educação Física com classificação A2, B1 e B2 pelo Qualis da Coordenação de Aperfeiçoamento de Pessoal de Nível Superior (CAPES), considerando o quadriênio de 2013 a 2016. Para tanto, foram visitados os sites das revistas que estavam on-line para a seleção dos artigos do estudo. As revistas selecionadas para a busca dos artigos foram: Revista Brasileira de Ciências do Movimento, Revista Brasileira de Ciências do Esporte, Revista Brasileira de Cineantropometria e Desempenho Humano, Revista Brasileira de Educação Física e Esporte, Revista da Educação Física, Revista Licere, Revista Motriz, Revista Movimento e Revista Pensar a Prática.

Os descritores utilizados para busca nos sites das revistas foram: "atividade de aventura" e "esporte de aventura". Para a seleção dos artigos foram utilizados os seguintes critérios de inclusão: 
a) intervenção no âmbito escolar, b) atividades/esportes de aventura; e os critérios de exclusão: a) abordagem fora do contexto escolar, b) foco no nível superior, c) público-alvo fora de idade escolar, d) contexto do lazer ou turismo. Com intenção de dar maior qualidade e credibilidade metodológica, o processo de seleção dos artigos foi feito pelo pesquisador e, em seguida, de maneira separada, para que não houvesse possibilidade de ser influenciado nos resultados, repetido por um colaborador que atua na mesma área de conhecimento, respeitando o objetivo do estudo, bem como os critérios de seleção e de exclusão,

Mediante a adoção dos descritores do estudo a busca inicial resultou em um total de 150 artigos. Em seguida, foi feita a busca pelos duplicados, ocasionando a exclusão de 50 artigos. Dos 100 artigos restantes para análise mais criteriosa, três foram excluídos por não apresentar o texto na íntegra. Ao realizar a leitura de todos os títulos e dos resumos, respeitando os critérios de inclusão e de exclusão do estudo, restaram 12 estudos. Ao dar continuidade, procedendo à leitura dos textos na íntegra, foram selecionados cinco artigos. 
Figura 1 - Fluxograma de busca dos estudos.

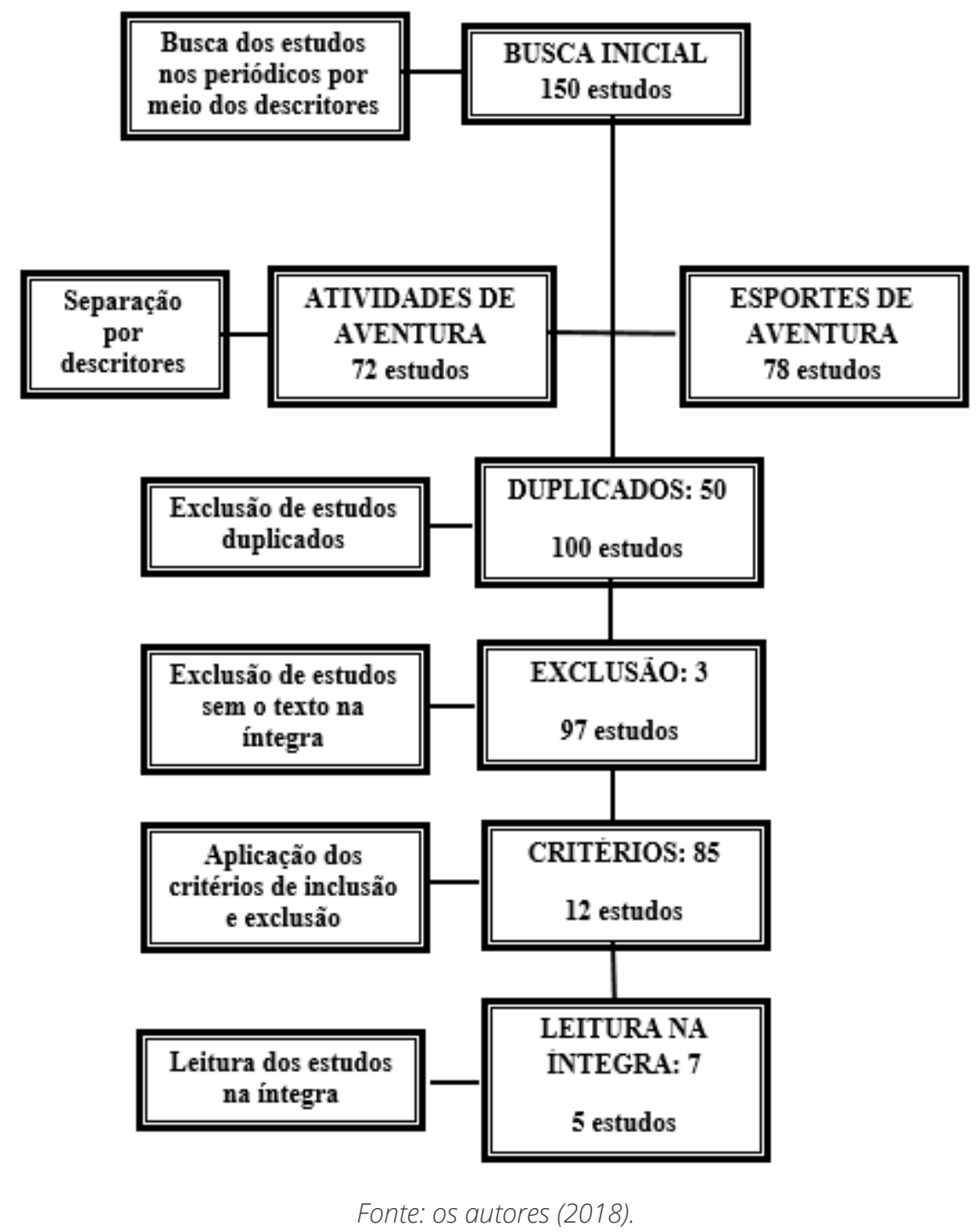

Ressalta-se que a análise desses cinco artigos foi realizada por meio da análise de conteúdo, seguindo as orientações de Bardin (1977), que estabelece três categorias: pré-análise, realizada por meio da leitura dos estudos baixados em versão $p d f$ na íntegra; codificação, em que foram criadas unidades de registro baseadas nos critérios de inclusão e exclusão estabelecidos; e categorização, realizada por meio de três categorias de análise (objetivo, método e principais resultados). 


\section{Resultados e discussão}

A busca inicial considerou os descritores atividades de aventura e esportes de aventura, que estão representados na tabela 1. Considerando esses critérios ao realizar a busca nos sites dos periódicos investigados foram encontrados 72 artigos com o descritor atividades de aventura e 78 artigos com o descritor esportes de aventura, totalizando 150 artigos.

Tabela 1 - Busca considerando os descritores do estudo.

\begin{tabular}{lccc}
\hline Periódicos & $\begin{array}{c}\text { Atividades de } \\
\text { Aventura }\end{array}$ & $\begin{array}{c}\text { Esportes de } \\
\text { Aventura }\end{array}$ & Total \\
\hline Rev. Brasileira de Ciência e Movimento & 0 & 4 & 4 \\
Rev. Brasileira de Ciências do Esporte & 12 & 9 & 21 \\
Rev. Brasileira de Cineantropometria e Desempenho & 0 & 1 & 1 \\
Humano & 1 & 1 & 2 \\
Rev. Brasileira de Educação Física e Esporte & 4 & 6 & 10 \\
Rev. da Educação Física/UEM & 8 & 5 & 13 \\
Rev. Licere & 32 & 35 & 67 \\
Rev. Motriz & 8 & 6 & 14 \\
Rev. Movimento & 7 & 11 & 18 \\
Rev. Pensar a Prática & 72 & 78 & 150 \\
\hline TOTAL
\end{tabular}

Fonte: os autores (2018).

Ao realizar uma busca extensa nos periódicos em abril do ano de 2016, revisada em junho de 2018, foi perceptível a escassez de estudos que abordam as atividades de aventura e os esportes de aventura no âmbito escolar. Assim, dos 150 artigos encontrados na busca inicial, a maior parte deles encontra-se publicado na Revista Motriz (67 artigos). Entre os selecionados, após a exclusão dos duplicados e leitura de resumo e texto completo, apenas artigos da Revista Brasileira de Educação Física e Esporte, Revista da Educação Física, Revista Licere, Revista Pensar a Prática e Revista Motriz corresponderam ao objetivo do estudo (Tabela 2). 
Tabela 2 - Busca dos estudos nos periódicos.

\begin{tabular}{lcccc}
\hline Periódicos & $\begin{array}{c}\text { Procura } \\
\text { Inicial }\end{array}$ & Duplicados & $\begin{array}{c}\text { Resumo e } \\
\text { Texto Completo }\end{array}$ & Selecionados \\
\hline Rev. Brasileira de Ciência e Movimento & 4 & 0 & 4 & 0 \\
Rev. Brasileira de Ciências do Esporte & 21 & 9 & 12 & 0 \\
Rev. Brasileira de Cineantropometria e & 1 & 0 & 1 & 0 \\
Desempenho Humano & & & 1 & 1 \\
Rev. Brasileira de Educação Física e & 2 & 1 & & 1 \\
Esporte & 10 & 4 & 6 & 1 \\
Rev. da Educação Física & 13 & 1 & 12 & 8 \\
Rev. Licere & 67 & 26 & 41 & 0 \\
Rev. Motriz & 14 & 5 & 9 & 1 \\
Rev. Movimento & 18 & 4 & 11 & 12 \\
Rev. Pensar a Prática & 150 & 50 & 97 & \\
\hline TOTAL & & & & \\
\hline
\end{tabular}

Fonte: os autores (2018).

Após a seleção dos 150 artigos, ao realizar a leitura do título e dos resumos foram encontrados 12 artigos, publicados em diferentes periódicos, que se encontram listados no Quadro 1.

Quadro 1 - Estudos selecionados para leitura na íntegra.

\begin{tabular}{|l|l|c|}
\hline \multicolumn{1}{|c|}{ Título } & \multicolumn{1}{|c|}{ Autores } & Ano \\
\hline $\begin{array}{l}\text { Práticas Corporais alternativas: formação em Educa- } \\
\text { ção Física }\end{array}$ & $\begin{array}{l}\text { Auria de Oliveira Carneiro Coldebella, } \\
\text { Luiz Alberto Lorenzetto, Arlei Colde- } \\
\text { bella }\end{array}$ & 2004 \\
\hline $\begin{array}{l}\text { A educação pela aventura: desmistificando sensa- } \\
\text { ções e emoções }\end{array}$ & $\begin{array}{l}\text { Aercio Rossi Cardoso, Andreia Silva, } \\
\text { Gisele Rosa Felipe }\end{array}$ & 2006 \\
\hline O brincar: linguagem da infância, língua do infantil & $\begin{array}{l}\text { Fernando Donizete Alves, Aline } \\
\text { Sommerhalder }\end{array}$ & 2006 \\
\hline $\begin{array}{l}\text { Carta internacional de educação para o lazer como } \\
\text { ferramenta de intervenção pedagógica efetiva no } \\
\text { campo do saber }\end{array}$ & $\begin{array}{l}\text { Renata Laudares Silva, Maria Luiza } \\
\text { Raphael, Fernanda Silva dos Santos }\end{array}$ & 2006 \\
\hline O circo na escola & Cinthia Ramos Pereira Vendruscolo & 2009 \\
\hline $\begin{array}{l}\text { Emoções e riscos nas práticas na natureza: uma } \\
\text { revisão sistemática }\end{array}$ & $\begin{array}{l}\text { Priscilla Pinto Costa da Silva, Clara } \\
\text { Maria Silvestre Monteiro de Freitas }\end{array}$ & 2010 \\
\hline
\end{tabular}




\begin{tabular}{|l|l|l|}
\hline $\begin{array}{l}\text { Estruturantes da base de conhecimentos para o en- } \\
\text { sino de estudantes-professores de Educação Física }\end{array}$ & $\begin{array}{l}\text { Daniel Marcon, Amândio Braga dos } \\
\text { Santos Graça, Juarez Vieira do Nasci- } \\
\text { mento }\end{array}$ & 2010 \\
\hline $\begin{array}{l}\text { Atividades de aventura: reflexões sobre a produção } \\
\text { científica brasileira }\end{array}$ & $\begin{array}{l}\text { Fabiano Augusto Teixeira, Alcyane } \\
\text { Marinho }\end{array}$ & 2010 \\
\hline O Skate e suas possibilidades educacionais & $\begin{array}{l}\text { Igor Armbrust, Flávio Antônio Ascânio } \\
\text { Lauro }\end{array}$ & 2010 \\
\hline $\begin{array}{l}\text { Recreação esportiva e seus desafios corporais no } \\
\text { Complexo do Alemão. }\end{array}$ & $\begin{array}{l}\text { Ângela Ferreira Tavares, Vera Lúcia de } \\
\text { Meneses Costa, Manoel José Gomes } \\
\text { Tubino }\end{array}$ & 2010 \\
\hline $\begin{array}{l}\text { Os conteúdos escolares das disciplinas de história e e } \\
\text { ciências e suas relaçães com a organização curricu- } \\
\text { lar da Educação Física na escola }\end{array}$ & $\begin{array}{l}\text { Luís Fernando Rocha Rosário, } \\
\text { Suraya Cristina Darido }\end{array}$ & 2012 \\
\hline $\begin{array}{l}\text { Educação física escolar e programa segundo tempo: } \\
\text { uma experiência de articulação curricular no Centro } \\
\text { Pedagógico/UFMG }\end{array}$ & $\begin{array}{l}\text { Guilherme Carvalho Franco da Silveira, } \\
\text { Freitas, Nayara Cristina Albanez }\end{array}$ & 2016 \\
\hline
\end{tabular}

Fonte: os autores (2018).

No entanto, após a leitura do texto na íntegra e a inserção de um terceiro pesquisador, que buscou consenso nos artigos, somente cinco artigos enquadraram-se nos critérios do estudo.

Os artigos selecionados foram analisados a partir das seguintes categorias: objetivo, método e principais resultados. No que tange aos objetivos, eles se reportam aos conteúdos da Educação Física e sua relação com as disciplinas de história e ciências, às práticas corporais alternativas na percepção de professores escolares e universitários, aos conteúdos da Educação Física nos anos finais do ensino fundamental, à literatura especializada, ao currículo de uma universidade pública e aos conteúdos presentes na Carta Internacional de Educação para o Lazer.

$\mathrm{Na}$ busca inicial, esperava-se encontrar estudos centrados nas atividades de aventura e nos esportes de aventura no contexto escolar, visto que esse conteúdo está inserido nas propostas pe- 
dagógicas das redes municipais e estaduais de ensino. Entretanto, ao pesquisar mais a fundo sobre o tema, pode-se perceber que essa dificuldade não se limita apenas ao cenário nacional, embora a legislação e pesquisadores tenham fomentado essa área de conhecimento (BORBA; AZEVEDO, 2007; INÁCIO et al., 2016; BRASIL, 2017; BUNGENSTAB et al., 2017; PAIXÃO, 2017).

A investigação de Coldebella, Lorenzetto e Coldebella, (2004), cujo objetivo estava realmente centrado nas práticas corporais alternativas, foi o que, de certa forma, se aproximou do objetivo desta pesquisa, bem como o de Hyndman (2016), que investigou a percepção das crianças de escolas primárias e secundárias para melhorar o ambiente de atividade física escolar na Austrália. $\mathrm{O}$ estudo revelou a atividade física de aventura, por exemplo a parede de escalada, entre outras atividades, como modalidades desejadas para estimular a atividade física. Com foco na educação especial, Zachor et al. (2016) examinaram a eficácia de um programa de atividades de aventura ao ar livre em crianças autistas. O estudo revelou melhora significativa na comunicação social, já que as atividades exigiam habilidades para resolver problemas e forçavam a criança a se comunicar em situações emocionantes.

Quando é feita a análise em relação aos objetivos, pode-se considerar que cada estudo se apresentou de forma distinta, tendo em vista a natureza das investigações, além de indicar as diferentes populações que foram investigadas. Os estudos em geral apresentam somente um objetivo principal do estudo (COLDEBELLA; LORENZETTO; COLDEBELLA, 2004; SILVA; RAPHAEL; SANTOS, 2006; SILVEIRA et al., 2016; ROSÁRIO; DARIDO, 2012), apenas o estudo de Tavares, Costa e Tubino (2010) apresenta mais de um objetivo (Quadro 2). 
Quadro 2 - Descrição dos objetivos dos estudos selecionados.

\begin{tabular}{|l|l|}
\hline \multicolumn{1}{|c|}{ Título } & \multicolumn{1}{|c|}{ Objetivos } \\
\hline $\begin{array}{l}\text { Práticas Corporais alternativas: for- } \\
\text { mação em Educação Física. }\end{array}$ & $\begin{array}{l}\text { - Investigar a perspectiva dos professores de Educação Física dos } \\
\text { ensinos fundamental, médio e superior sobre as PCAs na forma- } \\
\text { ção e atuação profissional. }\end{array}$ \\
\hline $\begin{array}{l}\text { Carta internacional de educação para } \\
\text { o lazer como ferramenta de interven- } \\
\text { ção pedagógica efetiva no campo do } \\
\text { saber. }\end{array}$ & $\begin{array}{l}\text { - Discutir junto à literatura especializada, os conteúdos presen- } \\
\text { de nue forta Internacional de Educação para o Lazer, para saber } \\
\text { de intervenção pedagógica e de que maneira se pode usá-los no } \\
\text { cotidiano das relações sociais e educativas. }\end{array}$ \\
\hline $\begin{array}{l}\text { Recreação Esportiva e seus desafios } \\
\text { corporais no Complexo do Alemão. }\end{array}$ & $\begin{array}{l}\text { - Identificar crianças de } 7 \text { a } 12 \text { anos afastadas da escola. } \\
\text { - Desenvolver os fundamentos básicos das modalidades de es- } \\
\text { portes coletivos e da ginástica artística com o enfoque na recre- } \\
\text { ação. }\end{array}$ \\
- Desenvolver temas pedagógicos bimestrais para buscar o me- \\
Ihor comportamento das crianças.
\end{tabular}

Fonte: os autores (2018).

No que se refere ao método adotado pelos pesquisadores, quatro artigos apresentam a abordagem qualitativa dos dados (SILVA; RAPHAEL; SANTOS, 2006; TAVARES; COSTA; TUBINO, 2010; SILVEIRA et al., 2016; ROSÁRIO; DARIDO, 2012), enquanto apenas um estudo apresenta uma abordagem quantitativa (COLDEBELLA; LORENZETTO; COLDEBELLA, 2004). No cenário internacional, são encontradas pesquisas com abordagem tanto qualitativa (JELALIAN et al., 2006; Ll et al., 2013; CHUNG et al., 2015) quanto quantitativa (BUCKLEY, 2016; HYNDMAN, 2016; TRACEY et al., 2018), porém os estudos vinculados ao âmbito da escola e que buscam a dimensão de conteúdos e as suas propriedades na intervenção tendem a obter uma abordagem qualitativa dos dados. 
Os estudos foram caracterizados como relato de experiência (TAVARES; COSTA; TUBINO, 2010), estudo documental (SILVA; RAPHAEL; SANTOS, 2006; SILVEIRA et al., 2016; ROSÁRIO; DARIDO, 2012) e estudo descritivo (COLDEBELLA; LORENZETTO; COLDEBELLA, 2004). A demanda de investigações sobre a problemática em questão envolve um cenário de associações de conhecimentos que extrapolam as pesquisas teóricas e carecem de investigações, aplicadas de modo a compreender o cotidiano de intervenção na escola. Todavia, não buscando generalizar os dados, considera-se relevantes estudos descritivos para a melhor compreensão do tema (Quadro 3).

Dos artigos investigados, dois buscaram analisar documentos referentes aos livros didáticos e documentos internacionais que repercutem na comunidade acadêmica e científica. Assim, o estudo de Silva, Raphael e Santos (2006) utilizou como fonte de coleta de dados a Carta Internacional de Educação para o Lazer, enquanto o estudo de Rosário e Darido (2012) analisou os livros didáticos escolares das disciplinas de história e ciências do $6^{\circ}$ ao $9^{\circ}$ ano do ensino fundamental, de modo a buscar a relação destas áreas de conhecimento com a Educação Física.

O estudo de Silveira et al. (2016) também envolveu análise documental, mas com foco na relação entre a produção acadêmica existente e as propostas pedagógicas do Centro Pedagógico da UFMG e do Programa Segundo Tempo do Ministério do Esporte. Além disso, promoveu grupos de discussão entre os autores que são relatados ao longo do artigo. Pode-se destacar que os estudos documentais visam à identificação de produções científicas referentes a determinado tema, respeitando procedimentos de descrição das etapas e especificação dos instrumentos utilizados (GUIMARÃES, 2009; TREINTA et al., 2014). Estudos documentais apresentam excelente contribuição para a literatura, pois possibilitam a análise de dados encontrados em documentos oficiais, livros, planos de trabalho, cartas, entre outros.

O artigo de Coldebella, Lorenzetto e Coldebella (2004) realizou a coleta de dados com professores de ensino fundamental e de 
ensino médio das redes pública e particular e com professores do ensino superior de universidades paulistas, por meio de um questionário. O estudo de Tavares, Costa e Tubino (2010) é caracterizado como um relato de experiência, que buscou relatar as ações e as práticas desenvolvidas no Projeto Cultura Corporal Esporte e Lazer no Complexo do Alemão, que agregava alunos fora da escola.

Quadro 3 - Caracterização dos estudos em relação ao método.

\begin{tabular}{|c|c|c|c|c|}
\hline Autor & Título & $\begin{array}{c}\text { Abordagem } \\
\text { estudo }\end{array}$ & $\begin{array}{l}\text { Tipo de } \\
\text { estudo }\end{array}$ & $\begin{array}{c}\text { Fonte de } \\
\text { informações }\end{array}$ \\
\hline $\begin{array}{l}\text { Auria de Oliveira } \\
\text { Carneiro } \\
\text { Coldebella; Luiz } \\
\text { Alberto Lorenzetto; } \\
\text { Arlei Coldebella }\end{array}$ & $\begin{array}{l}\text { Práticas Corporais alternati- } \\
\text { vas: formação em Educação } \\
\text { Física }\end{array}$ & Quantitativa & $\begin{array}{l}\text { Estudo } \\
\text { descritivo }\end{array}$ & Questionário \\
\hline $\begin{array}{l}\text { Renata Laudares } \\
\text { Silva; } \\
\text { Maria Luiza } \\
\text { Raphael; } \\
\text { Fernanda Silva dos } \\
\text { Santos }\end{array}$ & $\begin{array}{l}\text { Carta internacional de edu- } \\
\text { cação para o lazer como } \\
\text { ferramenta de intervenção } \\
\text { pedagógica efetiva no cam- } \\
\text { po do saber }\end{array}$ & Qualitativa & $\begin{array}{l}\text { Estudo } \\
\text { documental }\end{array}$ & $\begin{array}{l}\text { Carta internacional } \\
\text { de educação para o } \\
\text { lazer }\end{array}$ \\
\hline $\begin{array}{l}\text { Ângela Ferreira } \\
\text { Tavares; } \\
\text { Vera Lúcia de } \\
\text { Meneses Costa; } \\
\text { Manoel José } \\
\text { Gomes Tubino }\end{array}$ & $\begin{array}{l}\text { Recreação Esportiva e seus } \\
\text { desafios corporais no Com- } \\
\text { plexo do Alemão }\end{array}$ & Qualitativa & $\begin{array}{l}\text { Relato de } \\
\text { experiência }\end{array}$ & $\begin{array}{l}\text { Projeto cultura cor- } \\
\text { poral, esporte e lazer }\end{array}$ \\
\hline $\begin{array}{l}\text { Guilherme } \\
\text { Carvalho Franco da } \\
\text { Silveira; } \\
\text { Túlio Campos; } \\
\text { Amanda Fonseca } \\
\text { Soares Freitas; } \\
\text { Nayara Cristina } \\
\text { Albanez }\end{array}$ & $\begin{array}{l}\text { Educação física escolar e } \\
\text { programa segundo tempo: } \\
\text { uma experiência de articu- } \\
\text { lação curricular no Centro } \\
\text { Pedagógico/UFMG }\end{array}$ & Qualitativa & $\begin{array}{l}\text { Estudo } \\
\text { documental }\end{array}$ & $\begin{array}{l}\text { Propostas pedagógi- } \\
\text { cas da Educação Físi- } \\
\text { ca do Centro Pedagó- } \\
\text { gico e do Programa } \\
\text { Segundo Tempo no } \\
\text { Ministério do Espor- } \\
\text { te. }\end{array}$ \\
\hline
\end{tabular}

Fonte: os autores (2018).

No que tange aos resultados de cada artigo, o estudo de Rosário e Darido (2012) levantou a discussão sobre a sistematização dos conteúdos da Educação Física vinculados a outras disciplinas curriculares. Essa sistematização tem como principal finali- 
dade a organização desses conteúdos, de modo que o aluno não tenha o mesmo conteúdo aplicado com a mesma didática do $6^{\circ}$ ao $9^{\circ}$ ano. No entanto, adotando esse método, é possível que essa organização não considere o contexto do aluno e da escola e aplique conteúdos que não interessam a ambos.

Silva, Raphael e Santos (2006) analisaram um documento internacional, a Carta Internacional de Educação para o Lazer, como ferramenta de intervenção pedagógica efetiva no campo do Saber, em comparação com a literatura pertinente à temática e a possível utilização desse tema para a intervenção dentro da escola. Essa intervenção pode ser justificada com a abordagem das dimensões atitudinais evidentes nas atividades de lazer, considerando que "a escola é evidenciada como um dos pilares básicos na sociedade para a formação moral, cívica e ética dos indivíduos e, também, da própria comunidade a qual se encontra inserida" (p. 125).

Ao comparar o sentimento resultante do contato com as atividades de aventura, o estudo de Tavares, Costa e Tubino (2010) destacou a superação dos envolvidos nas performances frustradas em modalidades menos praticadas e na melhora nos domínios cognitivos, afetivo-social e psicomotor, e a autoestima. Ainda se referindo a esse estudo, um dos objetivos traçados seria a identificação de crianças de 7 a 12 anos afastadas da escola. O projeto apresentou um total de 278 inscritos, com efetivamente 108 crianças frequentadoras das aulas de Recreação Esportiva, e identificou somente 16 fora da escola. Esse número ainda não é de satisfação total, porém há de se destacar que, embora não consiga resolver esse problema, o projeto está auxiliando na melhoria da educação de jovens com vulnerabilidade social (TAVARES; COSTA; TUBINO, 2010).

O estudo de Silveira et al. (2016) mostra que a articulação experimental entre os projetos pedagógicos de Educação Física do Centro Pedagógico e o Programa Segundo Tempo pode proporcionar o enriquecimento da aprendizagem de práticas corporais em escolas de tempo integral. Além disso, pode permitir aos profes- 
sores de Educação Física a elaboração de possibilidades práticas e teóricas de aplicação dos conteúdos de ambas as propostas.

O estudo de Silva, Raphael e Santos (2006) sobre a Carta Internacional de Educação para o Lazer destaca que uma das metas da Word Leisure and Recreation Association é ajudar os estudantes a "(...) alcançar uma qualidade de vida desejável por meio da ampliação e promoção de valores, atitudes, conhecimentos e aptidões de lazer por meio do desenvolvimento pessoal, social, físico, emocional e intelectual (...)", estendendo este "(...) impacto na família, comunidade e sociedade" (SILVA; RAPHAEL; SANTOS, 2006, p. 125).

No que se refere ao estudo de Coldebella, Lorenzetto e Coldebella (2004), a amostra foi composta tanto por professores atuantes no ensino de nível escolar (fundamental e médio) como por professores universitários, sendo estes aproximadamente 50\% da amostra. Quanto aos resultados, percebeu-se que mais de $61 \%$ dos entrevistados não cursaram qualquer disciplina que tivesse relação com as Práticas Corporais Alternativas em sua formação.

Nesse mesmo estudo, mais de $84 \%$ dos professores da amostra consideraram necessária a inclusão da disciplina Práticas Corporais Alternativas no currículo da Educação Física. Além disso, mais de $76 \%$ dos professores que opinaram, relataram que durante as práticas na Educação Física no ensino fundamental e no ensino médio apresentam aos alunos outra forma de atuar sobre o corpo, ajudando-os a ter maior consciência corporal, a relaxar e a descontrair. A justificativa para o trabalho com as Práticas Corporais Alternativas nas aulas de Educação Física da educação básica corresponde à necessidade demonstrada pela preocupação dos professores com uma Educação Física voltada para as diferentes dimensões do ser humano (COLDEBELLA; LORENZETTO; COLDEBELLA, 2004).

Ao considerar os resultados dos estudos investigados, nota-se a preocupação dos pesquisadores em relatar a importância de intervenções e projetos para além do contraturno escolar. Essa re- 
levância se deve à gama de possibilidades em inserir as atividades e os esportes de aventura nas aulas de Educação Física. É notório nos estudos o grande valor do conteúdo que possibilita conhecimentos voltados para, além dos princípios atitudinais, a melhoria da qualidade de vida. Por outro lado, a incipiência de estudos e de disciplinas na formação inicial pode ser um grave empecilho para abordar as atividades de aventura e os esportes de aventura no contexto escolar. Com isso, cabe ao professor de Educação Física buscar respaldo na legislação e em propostas curriculares para subsidiar a sua prática diária.

\section{Considerações finais}

Como proposta para esta análise, foi realizado um levantamento em periódicos da área da Educação Física, seguido de leitura dos títulos, resumos e artigos, a fim de filtrar de acordo com critérios de inclusão e exclusão. No entanto, houve dificuldade de encontrar estudos relacionados ao tema, fato que se tornou uma limitação do estudo. Cabe destacar que os estudos selecionados no primeiro momento tinham relação com aventura, porém estavam fora do contexto escolar, ou faziam referência às áreas de lazer e turismo, além de alguns em que seu público-alvo não condizia com a idade escolar, o que não atendia ao objetivo do estudo.

Pode-se concluir que, dos artigos relacionados na pesquisa, apenas cinco continham dados que puderam colaborar na investigação, porém com assuntos distintos. Destaca-se que as investigações apresentavam a relação dos conteúdos relacionados às práticas de aventura na escola com algumas dimensões do processo de intervenção: os conteúdos de ciências e história e a história do ser humano com a natureza, bem como assuntos relacionados ao conteúdo que é abordado nas aulas de Educação Física. Além disso, as investigações apresentaram aspectos relativos à dimensão atitudinal e aos conteúdos alternativos para intervenção escolar, com professores de instituições públicas e privadas. 
Por fim, esperava-se encontrar um contingente maior de estudos nos periódicos investigados. Todavia, considera-se que o objetivo inicial foi atingido, revelando que há a necessidade de ampliar as investigações e publicações sobre o tema atividades de aventura e esportes de aventura. Assim, recomenda-se a realização de outros estudos com a mesma proposta metodológica, mas em outros periódicos nacionais e bases internacionais, na perspectiva de encontrar um número maior de investigações.

\section{Referências}

ALVES, F. D.; SOMMERHALDER, A. O brincar: linguagem da infância, língua do infantil. Motriz, Rio Claro, v. 12, n. 2, p. 125-132, 2006.

ARMBRUST, I.; LAURO, F. A. A. O Skate e suas possibilidades educacionais. Motriz, Rio Claro, v. 16, n. 3, p. 799-807, 2010.

AURICCHIO, J. R. Formação dos profissionais da cidade de Socorro- SP em atividades de aventura no âmbito do lazer. Licere, Belo Horizonte, v. 20, n. 1, 2017.

BARDIN, L. Análise de conteúdo. Lisboa: Edições 70 Ltda, 1977. BORBA, A. C.; AZEVEDO, A. C. B. A escalada como conteúdo da Educação Física Escolar: uma experiência de trabalho com portadores de necessidades especiais no Instituto Benjamin Constant. In: ENCONTRO FLUMINENSE DE EDUCAÇÃO FÍSICA ESCOLAR, 11., 2007, Rio de Janeiro. Anais... Rio de Janeiro: UFF, 2007. p. 60-70.

BRASIL. Lei n 9.394, de 20 de dezembro de 1996, que estabelece as diretrizes e bases da educação nacional. Lei de diretrizes e bases da educação nacional, Câmara dos Deputados, Brasília, DF, ed. 11, 29 dez. 1996.

BRASIL. Lei n 9.795, de 27 de abril de 1998, que dispõe a política nacional de educação ambiental. Lei da política nacional de 
educação ambiental, Câmara dos Deputados, Brasília, DF, ed. 11, 17 abr. 1999.

BRASIL. Ministério da educação. Base nacional curricular comum. Brasília: MEC, v. 2, 2017.

BRASIL. Ministério da educação. Secretaria da educação fundamental. Parâmetros curriculares nacionais: Educação Física. Brasília: MEC/SEF, 1998.

BRASIL. Ministério da educação. Secretaria de educação básica. Secretaria de educação continuada, alfabetização, diversidade e inclusão. Secretaria de educação profissional e tecnológica. Conselho nacional de educação. Câmara nacional de educação básica. Diretrizes curriculares gerais da educação básica Brasília: MEC/SEB/DICEI, 2013.

BUCKLEY, R. C. Qualitative Analysis of Emotions: Fear and Thrill. Frontiers In Psychology, Lausanne, v. 7, p. 1-13, 2016. BUNGENSTAB, G. C.; SANTOS, W. M.; SILVA, L. T.; SANTOS, R. M. A.; HOLANDA, G. I. S.; RAMOS, J. S. D.; GUEDES, D. G. S. Educação Física no Ensino Médio: Possibilidades de Ensino das Práticas Corporais (de Aventura), Corpoconsciência, Cuiabá-MT, v. 21, n. 3, p. 29-40, 2017.

CARDOSO, A. R.; SILVA, A.; FELIPE, G. R. A educação pela aventura: desmistificando sensações e emoções. Motriz, Rio Claro, v. 12, n. 1, p. 77-87, 2006.

CHUNG, O. K. J. et al. Sustainability of an Integrated AdventureBased Training and Health Education Program to Enhance Quality of Life Among Chinese Childhood Cancer Survivors. Cancer Nursing, New York, v. 38, n. 5, p. 366-374, 2015.

COLDEBELLA, A. O. C.; LORENZETTO, L. A.; COLDEBELLA, A. Práticas corporais alternativas: formação em Educação Física. Motriz, São Paulo, v. 10, n. 2, p. 111-122, 2004.

FIGUEIREDO, J. P.; SCHWARTZ, G. M. Atividades de aventura e educação ambiental como foco nos periódicos da área de Educação Física, Motriz, v. 19, n. 2, p. 467-479, 2013. 
FRANCO, L. C. P. Atividades físicas de aventura nas escolas. In: BERNARDES, L. A. (Org.). Atividades e esportes de aventura para profissionais de Educação Física. São Paulo: Phorte, 2013. p. 207-226.

FRANCO, L. C. P.; CAVASINI, R.; DARIDO, S. C. Práticas corporais de aventura. In: GONZÁLEZ, F. J.; DARIDO, S. C.; OLIVEIRA, A. A. B. (Orgs.). Lutas, capoeira e práticas corporais de aventura: práticas corporais e a organização do conhecimento. Maringá, PR: Ed. UEM, 2014.

GUIMARÃES, A. A.; PELLINI, F. C.; ARAUJO, J. S. R.; MAZZINI, J. M. Educação Física escolar: valores e atitudes. Motriz, São Paulo, v. 7, n. 1, p. 17-22, 2001.

GUIMARAES, J. A. C. Abordagens teóricas de tratamento temático da informação (TTI): catalogação de assunto, indexação e análise documental. In: GARCÍA MARCO, F. J. (Org). Avanços e perspectivas em sistemas de informação e documentação. 3. ed. Ibersid: Zaragoza, 2009. p. 105-117.

HYNDMAN, B. A. Qualitative Investigation of Australian Youth Perceptions to Enhance School Physical Activity: The Environmental Perceptions Investigation of Children's Physical Activity (EPIC-PA) Study. Journal Of Physical Activity And Health, Londrina, v. 13, n. 5, p. 543-550, 2016.

INÁCIO, H. L. D.; CAUPER, D. A. C.; SILVA, L. A. P.; MORAIS, G. G. Práticas corporais de aventura na escola: possibilidades e desafios - reflexões para além da Base Nacional Comum Curricular. Motrivivência v. 28, n. 48, p. 168-187, 2016.

JELALIAN, E. et al. 'Adventure therapy' combined with cognitivebehavioral treatment for overweight adolescents. International Journal Of Obesity, London, v. 1, n. 30, p. 31-39, 2006.

LI, H. C. W. et al. Effectiveness of an integrated adventure-based training and health education program in promoting regular physical activity among childhood cancer survivors. Psychooncology, Chichester, v. 22, n. 11, p. 2601-2610, 2013. 
MARCON, D.; GRAÇA, A. B. S.; NASCIMENTO, J. V. Estruturantes da base de conhecimentos para o ensino de estudantes-professores de Educação Física. Motriz, Rio Claro, v. 16, n. 3, p. 776-787, 2010. PAIXÃO, J. A. Esporte de aventura como conteúdo possível nas aulas de Educação Física escolar. Motrivivência, Florianópolis, v. 29, n. 50, p. 170-182, 2017.

ROSÁRIO, L. F. R.; DARIDO, S. C. Os conteúdos escolares das disciplinas de história e ciências e suas relações com a organização curricular da Educação Física na escola. Revista Brasileira de Educação Física e Esporte, São Paulo, v. 26, n. 4, p. 691-704, 2012.

\section{SCAGLIA, A. J. Referencial Curricular da Educação básica das} Escolas Públicas Municipais de Franca, Franca SP, 2007.

SILVA, P. P. C.; FREITAS, C. M. S. M. Emoções e riscos nas práticas na natureza: uma revisão sistemática. Motriz, Rio Claro, v. 16, n. 1, p. 221-230, 2010.

SILVA, R. L.; RAPHAEL, M. L.; SANTOS, F. S. Carta internacional de educação para o lazer como ferramenta de intervenção pedagógica efetiva no campo do saber. Pensar a Prática, Goiânia, v. 9, n. 1, p. 117-131, 2006.

SILVEIRA, G. C. F.; CAMPOS, T.; FREITAS, A. F. S.; ALBANEZ, N. C. Educação Física escolar e programa segundo tempo: uma experiência de articulação curricular no centro pedagógico/ UFMG. Pensar a Prática, Goiânia, v. 19, n. 3, p. 688-701, 2016.

TAVARES, A. F.; COSTA, V. L. M.; TUBINO, M. J. G. Recreação esportiva e seus desafios corporais no Complexo do Alemão. Motriz, Rio Claro, v. 16, n. 1, p. 258-268, 2010.

TEIXEIRA, F. A.; MARINHO, A. Atividades de aventura: reflexões sobre a produção científica brasileira. Motriz, Rio Claro, v. 16, n. 3, p. 536-548, 2010.

TRACEY, D. et al. Combining Acceptance and Commitment Therapy With Adventure Therapy to Promote Psychological 
Wellbeing for Children At-Risk. Frontiers In Psychology, Lausanne, v. 9, p.1-9, 2018.

TREINTA, F. T.; FARIAS FILHO, J. R.; SANT'ANNA, A. P.; RABELO, L. M. Metodologia de pesquisa bibliográfica com a utilização de método multicritério de apoio à decisão. Prodiction, v. 24, n. 3, p. 508-520, 2014.

VENDRUSCOLO, C. R. P. O circo na escola. Motriz, Rio Claro, v. 15, n. 3, p. 729-737, 2009.

ZACHOR, D. et al. The effectiveness of an outdoor adventure programme for young children with autism spectrum disorder: a controlled study. Developmental Medicine \& Child Neurology, Oxford, v. 59, n. 5, p. 550-556, 2016.

\section{Publisher}

Universidade Federal de Goiás. Faculdade de Educação Física e Dança. Publicação no Portal de Periódicos UFG. As ideias expressadas neste artigo são de responsabilidade de seus autores, não representando, necessariamente, a opinião dos editores ou da universidade. 